\title{
Price elasticity of demand for cigarettes in Bosnia and Herzegovina: microdata analysis
}

\author{
Dragan Gligorić, ${ }^{1}$ Anđela Pepić 이, ${ }^{2}$ Saša Petković, ${ }^{1}$ Jovo Ateljević, ${ }^{1}$ Borislav Vukojević
}

${ }^{1}$ Faculty of Economics, University of Banja Luka, Banja Luka, Bosnia and Herzegovina ${ }^{2}$ Entrepreneurship and Technology Transfer Centre, University of Banja Luka, Banja Luka, Bosnia and Herzegovina ${ }^{3}$ Faculty of Political Sciences, University of Banja Luka, Banja Luka, Bosnia and Herzegovina

\section{Correspondence to}

Anđela Pepić, Entrepreneurship and Technology Transfer Centre, University of Banja Luka, Banja Luka 78000, Bosnia and Herzegovina;

andjela.pepic@unibl.org

Received 30 June 2019 Revised 11 December 2019 Accepted 6 January 2020 Published Online First 25 August 2020

\section{ABSTRACT}

Background Bosnia and Herzegovina $(B \& H)$ is among the top 10 countries in the world in terms of number of smokers. The cigarette prices in B\&H are under a direct impact of state excise tax policy. The specific excise on cigarettes was introduced in B\&H in 2009. Since then it has been increasing every year thus being the main driver of cigarette prices growth.

Methods In this paper we estimate price elasticity of demand for cigarettes following Deaton demand model and apply it on microdata obtained from the Household Budget Surveys in B\&H conducted in 2011 and 2015. Deaton model uses within-cluster information to estimate total expenditure elasticities and then uses between-cluster information to estimate price elasticities. For $\mathrm{B} \& \mathrm{H}$, the cluster is defined as a municipality $\times$ in the year t. Our sample contains 14252 households, divided into 267 clusters.

Results Our results show that the price elasticity is statistically significant and amounts to -1.366 . This means that if cigarette prices in $\mathrm{B} \& \mathrm{H}$ are increased by $10 \%$, the demand for cigarettes would decrease by $13.66 \%$.

Conclusions We found a negative price elasticity of demand for cigarettes of -1.366 . These results of the econometric estimate of elasticity of demand are more elastic compared with the results of similar surveys carried out on the sample of low and middle-income countries. It demonstrates that the demand for cigarettes responds strongly to the price increase.

\section{INTRODUCTION}

A large percentage of Bosnia and Herzegovina $(\mathrm{B} \& \mathrm{H})$ citizens is engaged in tobacco consumption. $\mathrm{B} \& \mathrm{H}$ is among the top 10 countries in the world in terms of number of smokers. ${ }^{1}$ According to the official statistics, nearly $40 \%$ of the state's adults (about 1200600 persons) consume tobacco products on a daily basis." 'The study showed that in all of the households surveyed, approximately $41 \%$ had an individual that smoked cigarettes. On average, $\mathrm{B} \& \mathrm{H}$ households, which have declared themselves to consume cigarettes (smoking households) spent an estimated $5.4 \%$ of the monthly budget on cigarettes. ${ }^{3}$ There is a strong socioeconomic gradient in smoking, with more financially secure people in $\mathrm{B} \& \mathrm{H}$ being less likely to smoke. Tax policy is one of the most effective means for reduction of tobacco products consumption as it is confirmed in almost all relevant studies carried out so far by the leading researchers in the field of health economics. ${ }^{4-6}$

In order to determine the effect of cigarette prices increase, it is necessary to estimate price elasticity. Evidence from countries of all income levels suggests that increase in cigarette prices is highly effective in reducing demand. ${ }^{7}$ Previous research, conducted in low and middle-income countries (LMIC), found that the price elasticity of demand for cigarettes is in the range of -0.5 to $-1 .^{8}$ This implies that in these countries increase in price of cigarettes can be effective in reducing demand for cigarettes.

The purpose of our research is to determine the relationship between increase of cigarette prices and demand for cigarettes in $\mathrm{B} \& \mathrm{H}$. In the absence of sufficiently long-time series data, as it is the situation in $\mathrm{B} \& \mathrm{H}$, Deaton demand model $^{9}$ is a more efficient model for estimating price elasticity of demand for cigarettes than the econometrics model based on the macrolevel data. In our methodological approach, we follow Deaton demand model and apply it on microdata, obtained from Household Budget Surveys (HBS) in B\&H. The study is the first of its kind in $\mathrm{B} \& \mathrm{H}$.

\section{DATA AND METHODS \\ Data and sample}

In this paper, we used HBS data obtained by B\&H's authorised statistics agencies for years 2011 and 2015. Aforementioned data were used in order to compile weightings for important macroeconomic indicators, including consumer price indices, household expenditure on goods and services that give a picture of living conditions in $\mathrm{B} \& \mathrm{H} .{ }^{10}{ }^{11}$ The data from the survey were broken down by household characteristics, such as income, socioeconomic characteristics, size and composition, degree of urbanisation and similar.

In accordance with the requirements of the Deaton model, first we define clusters. Our clusters are defined as a municipality $\times$ in the year t. According to this definition, we generate 271 clusters containing 14298 households. In each cluster, we have 53 households on average. Among full sample of households, 5859 households are reported as smoking households. Being a condition in order to estimate the Deaton model, each cluster must have at least two households. According to the criteria requested to apply Deaton model, we drop 42 households whose total household expenditure is 5 SDs higher than mean expenditure in the overall sample. Additionally, we drop four clusters which contain only one household. So, due to the Deaton model estimation procedure, we reduced the sample and it contains 267 clusters and 14252 households.

\section{Theoretical background}

Deaton demand model is a model of consumer behaviour in which households choose both quantity and quality. The expenditure on particular good in this model is the product of quantity, quality and 
price. Deaton ${ }^{12}$ provides detailed exposition of the methodology. Thus, we briefly describe the basic equations and procedure to estimate the price elasticity using HBS data.

Deaton model uses information within-cluster information to estimate the total expenditure elasticity and then uses betweencluster information to estimate price elasticity. Unit values, which are calculated from the households' consumption diary, are used as a proxy for price. In practice, unit values depend on the actual market prices, but cannot be used as direct substitutes for prices. Unit values are different from prices because there are measurement errors involved in quantity and variations in quality due to heterogeneous nature of the commodity. ${ }^{13}$ For example, in case of constant household budget, when the cigarette prices change, the household can decrease its cigarette consumption and stay with the same brand or redirect to less expensive brand and keep its consumption at the same level, which is referred to as quality shading.

Deaton model consists of two regression equations. The first equation is budget share of cigarettes equation (a proxy for demand) and the second equation is unit value equation (a proxy for price):

$$
\begin{gathered}
w_{b c}=\alpha^{0}+\beta^{0} \ln x_{b c}+\gamma^{0} \cdot z_{b c}+\theta \ln p_{c}+\left(f_{c}+u_{c h}^{0}\right) \\
\ln v_{b c}=\alpha^{1}+\beta^{1} \ln x_{b c}+\gamma^{1} \cdot z_{b c}+\psi \ln p_{c}+u_{b c}^{1}
\end{gathered}
$$

where indices $h$ and $c$ represent households and clusters, respectively. Variable $w_{b c}$ denotes the share of the household budget spent on cigarettes (in percentages) and $v_{b c}$ denotes unit values. Variable $x_{b c}$ is total expenditures of the household $h$ in cluster $c, z_{h c}$ denotes other household characteristics, $p_{c}$ is price of the cigarettes in cluster $c$, while $u_{c b}^{0}$ and $u_{b c}^{1}$ are the error terms. $f_{c}$ is a cluster fixed effect and treated as an error in addition to the error term $u_{c b}^{0}$ in equation (1). Due to the fact that cigarette prices are not reported in the consumption diary and consequently in HBS, we cannot estimate budget shares and the unit values described in equations (1) and (2) as such. Under the assumption that market prices do not vary for a given commodity within each cluster but vary between clusters we can include market prices by adding dummy variables for each cluster and the parameters $\beta^{0}, \beta^{1}, \gamma^{0}, \gamma^{1}$ in both equations can be consistently estimated by standard ordinary least squares. This is the first stage (household-level regression) of Deaton model estimation.

In the second stage of Deaton model estimation, we use the estimates from the first stage and remove the effects of the total household expenditure and other household characteristics from the budget shares and the unit values (ie, purging the quality effects):

$$
\begin{gathered}
\tilde{y}_{b c}^{0}=w_{b c}-\tilde{\beta}^{0} \ln x_{b c}-\widetilde{\gamma}^{0} z_{b c} \\
\tilde{y}_{b c}^{1}=\ln v_{b c}-\tilde{\beta}^{1} \ln x_{b c}-\tilde{\gamma}^{1} z_{b c}
\end{gathered}
$$

The dependent variables $\left(\tilde{y}_{b c}^{0}\right.$ and $\left.\tilde{y}_{b c}^{1}\right)$ in equations (3) and (4) contain the price information and we use it to create cluster averages of budget shares and unit values:

$$
\begin{gathered}
y_{c}^{0}=\alpha^{0}+\theta \ln p_{c}+f_{c}+u_{c}^{0} \\
y_{c}^{1}=\alpha^{1}+\psi \ln p_{c}+u_{c}^{1}
\end{gathered}
$$

After creating averages of budget shares and unit values on the cluster level, we can calculate how cluster-level demand (ie, cluster budget shares) responds to changes in cluster-level unit values. Thus, we calculate coefficient on cluster-level unit values by dividing covariance between cluster-level budget shares and cluster-level unit values by variance of cluster-level unit value:

$$
\hat{\phi}=\frac{\operatorname{cov}\left(\hat{\mathrm{y}}_{\mathrm{c}}^{0}, \hat{\mathrm{y}}_{\mathrm{c}}^{1}\right)-\hat{\sigma}^{01} / \mathrm{n}_{\mathrm{c}}}{\operatorname{var}\left(\hat{\mathrm{y}}_{\mathrm{c}}^{1}\right)-\hat{\sigma}^{11} / \mathrm{n}_{\mathrm{c}}+}
$$

where $\mathrm{n}_{c}$ is the number of all the households per cluster and $n_{c}^{+}$is the number of households with cigarette purchases.

However, coefficient on cluster-level unit values is not price elasticity. It is smaller than price elasticity due to the quality shading. To calculate the price elasticity of demand, in the third stage of Deaton model estimation, we rely on weak separability theory of quality and the definition of the budget share as the product of quantity of cigarettes and unit value divided by the total expenditures $\left(\mathrm{w}=\mathrm{q}^{*} \mathrm{v} / \mathrm{x}\right)$. From there it can be shown ${ }^{12}$ that the parameter $\theta$ can be calculated as:

$$
\theta=\phi /[1+w-\phi] \text { where } \zeta=\frac{\beta^{1}}{\beta^{0}+w\left(1-\beta^{1}\right)}
$$

where $\beta^{1}$ and $\beta^{0}$ are estimated from the equations (1) and (2), while $w$ is the average value of the budget share. If $\beta^{1}$ is small, $\zeta$ will be small, and so will be the correction to $\theta$ in equation (8); when the income elasticity of quality $\left(\beta^{1}\right)$ is small, there will be little shading of unit value in response to price. ${ }^{12}$

The formula for price elasticity of demand that we calculate by taking a log and first difference of budget share with respect of the price is ${ }^{12}$ :

$$
\epsilon_{p}\left(\frac{\theta}{w}\right)-\psi \text { where } \hat{\psi}=1-\frac{\beta^{1}(\hat{w}-\hat{\theta})}{\hat{\beta}^{0}+\hat{w}}
$$

Although Deaton model is primarily focused on efficient estimation price elasticities, Deaton proposes the formula for obtaining estimation of demand expenditure elasticity, which only uses data from first-stage (household-level) regression ${ }^{12}$ :

$$
\epsilon_{x}=1-\beta^{1}+\left(\frac{\beta^{0}}{w}\right)
$$

Due to the calculation procedure, SEs for both price and expenditure elasticity cannot be taken directly from the regression analyses. Instead, we use bootstrapping procedure to calculate the SE in order to determine the statistical significance of the estimated price and expenditure elasticity. The bootstrapped SE for the price elasticity is calculated by making 1000 draws from the cluster (second-stage) data, while SE for expenditure elasticity is calculated by making 1000 draws from the household (first-stage) data, according to the Deaton estimation procedure.

\section{Measures}

Unit value of cigarettes is calculated as a ratio of monthly household expenditure on cigarettes and the number of cigarette packs purchased by the household during a month. We express it in logarithmic form. Household expenditure on cigarettes from illicit market is included in this analysis because households report the total expenses on cigarettes and total cigarette consumption quantity regardless whether they buy it on official or illicit market. Budget share of cigarettes is calculated as a ratio of monthly household expenditure on cigarettes and the total monthly household expenditure. Both are deflated to their real values from 2011, by using Consumer Price Index. Other variables we use to estimate Deaton demand model are total monthly expenditures (ln), and the wide number of variables which represent household characteristics. Household variables include household size $(\ln )$, age and gender composition of the 


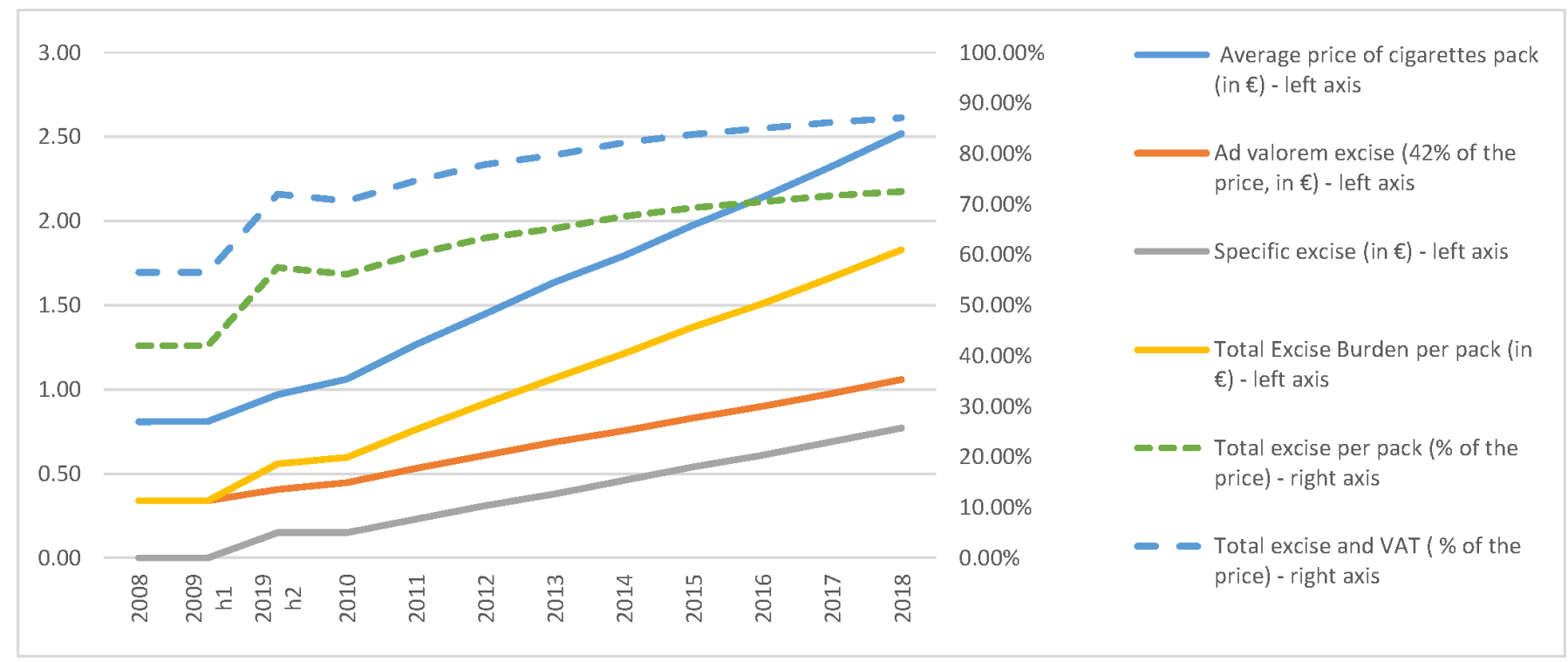

Figure 1 Average cigarette price, cigarette tax structure and excise burden in the period 2008-2018. Source: Authors' calculation based on the Indirect Taxation Authority data, 2019. VAT, value-added tax.

household, as well as the mean and maximum level of education of the household members. Adult ratio is the ratio between all household members and those older than 14. Maximum level of education is calculated taking into account all household members regardless of age. Urbanisation settlements are a dummy variable, which take value 1 if households are from urban settlements and 0 if households are from rural settlements. We control for the household type by economic activity, by taking the 'maximum' activity of the household members. The households are split into four household types: (1) employed, (2) self-employed, (3) pensioner, and (4) unemployed. ${ }^{14}$

\section{RESULTS}

\section{Descriptive statistics}

The price of cigarettes in $\mathrm{B} \& \mathrm{H}$ has increased significantly over the last 10 years. The introduction of a specific excise in the second half of 2009 and its increase in the coming period reflected the increase in the price of a cigarette pack. On introduction, specific excise has increased by about $€ 0.078$ every year, from an initial level of $€ 0.15$ per pack to $€ 0.77$ per pack in 2018. Ad valorem excise, calculated on the retail price of cigarettes, stayed at the same level of $42 \%$ retail price. This is the main reason for the increase in the average prices of cigarette for about $211.6 \%$, in the period 2008-2018. The average cigarette prices, cigarette tax structure and total excise burden are presented in figure 1 . The total excise burden per pack, calculated as a ratio of retail price and sum of ad valorem and specific excise per pack, increased from $42 \%$ of retail price in 2008 to $72.56 \%$ of retail price in 2018 .

The descriptive statistics of the variables used in the estimation of the Deaton model are presented in table 1. The data indicate that about $40.9 \%$ of the households have expenses on cigarettes (share of available observations on unit value).

The share of smoking households significantly declined from $48.3 \%$ in 2011 to $33.6 \%$ in 2015 . At the same time, the number of cigarette packs consumed per household decreased from 32.32 to 22.75 , or by $29.6 \%$. Total monthly expenditures (monthly household budget) were much lower in non-smoking households. The difference between smoking and non-smoking household budgets was $€ 232.61$ and $€ 238.51$ in 2011 and 2015, respectively. When we look at both years together, the difference is about $€ 241.61$.

Unit value of cigarettes, representing the changes in cigarette prices and the changes in the choice of cigarette quality (brands), increased from $€ 1.21$ to $€ 1.87$, or about $54.5 \%$. The average price of cigarettes, which was determined by the national statistical agency, increased from $€ 1.08$ to $€ 1.74$ or by $60.6 \%$. $^{15}$ Therefore, increase in unit value was lower than increase in cigarette prices. This is referred to as 'quality shading'. When the cigarette prices increase, due to the budget constraint, households substitute to less expensive brands and try to decrease their consumption as little as possible, that is, households shade

Table 1 Smoking households' monthly statistics

\begin{tabular}{|c|c|c|c|c|c|c|c|c|}
\hline Year & Household & $\begin{array}{l}\text { Households, } \\
\mathrm{n}\end{array}$ & Household (\%) & $\begin{array}{l}\text { Total } \\
\text { expenditures }(€)\end{array}$ & $\begin{array}{l}\text { Consumption of } \\
\text { cigarettes (in pack) }\end{array}$ & $\begin{array}{l}\text { Expenditures on } \\
\text { cigarettes }(€)\end{array}$ & $\begin{array}{l}\text { Unit value of } \\
\text { pack }(€)\end{array}$ & $\begin{array}{l}\text { Budget share on } \\
\text { cigarettes }(\%)^{21}\end{array}$ \\
\hline \multirow[t]{2}{*}{2011} & Non-smoking & 3628 & 51.7 & 672.71 & & & & \\
\hline & Smoking & 3396 & 48.3 & 905.32 & 32.32 & 39.08 & 1.21 & 5.18 \\
\hline 2015 & Smoking & 2432 & 33.6 & 868.22 & 22.75 & 42.67 & 1.87 & 5.71 \\
\hline 2011 and 2015 & Non-smoking & 8424 & 59.1 & 648.23 & & & & \\
\hline
\end{tabular}

Source: Authors' calculation based on the Household Budget Surveys (HBS) data. 


\begin{tabular}{|c|c|c|c|c|c|}
\hline Variable & Observation & Mean & SD & Min & Max \\
\hline Unit value, cigarettes (In) & 5828 & 1.0356 & 0.2514 & 0.1823 & 1.6831 \\
\hline Budget share, cigarettes & 14252 & 0.0221 & 0.0381 & 0.0000 & 0.6971 \\
\hline Total expenditure (In) & 14252 & 7.0811 & 0.6618 & 4.0405 & 8.7960 \\
\hline Household size (In) & 14252 & 0.9459 & 0.5732 & 0 & 2.7081 \\
\hline Male ratio & 14252 & 0.4646 & 0.2639 & 0 & 1 \\
\hline Adult ratio & 14252 & 0.8560 & 0.2055 & 0 & 1 \\
\hline Mean education & 14252 & 7.6337 & 3.6477 & 0 & 20 \\
\hline Maximum education & 14252 & 10.2453 & 4.0125 & 0 & 20 \\
\hline Urban settlements & 14252 & 0.3819 & 0.4859 & 0 & 1 \\
\hline \multicolumn{6}{|l|}{ Household type } \\
\hline Employed & 14252 & 0.5806 & 0.4934 & 0 & 1 \\
\hline Self-employed & 14252 & 0.2255 & 0.4180 & 0 & 1 \\
\hline Pensioners & 14252 & 0.1410 & 0.3480 & 0 & 1 \\
\hline Unemployed & 14252 & 0.0528 & 0.2236 & 0 & 1 \\
\hline
\end{tabular}

down both quality and quantity. Share in expenditures on cigarettes in total expenditures, among smoking households, has increased from $5.18 \%$ in 2011 to $5.71 \%$ in 2015 , as a result of both increase in cigarette prices and decrease in total household budgets.

The budget share of cigarettes, among all households, is presented in table 2 and shows that households spend about $2.2 \%$ of their budget on cigarettes. The households have average male ratio of about $46 \%$, while the children (ie, those aged 14 or less) represent about $14 \%$ of the household members. Mean and maximum years of education of 7.63 and 10.25 suggest that on average household members have a very low level of education, that is, primary level. ${ }^{16}$

About 38\% of the households are from urban areas, while approximately $58 \%$ have at least one person employed, while $22.5 \%$ of the households have at least one person self-employed. Household type 'pensioner' makes about 14.1\%, while household type 'unemployed' makes about $5.3 \%$ of the households.

\begin{tabular}{|c|c|c|c|c|}
\hline \multirow{2}{*}{$\begin{array}{l}\text { Variables } \\
\text { Total expenditure (In) }\end{array}$} & \multicolumn{2}{|c|}{ Unit value (per pack, In) } & \multicolumn{2}{|c|}{ Cigarette budget share (\%) } \\
\hline & $0.061^{* * *}$ & $(0.008)$ & $0.004^{* * *}$ & $(0.001)$ \\
\hline Household size (In) & $0.041^{* * *}$ & $(0.004)$ & $0.003^{* * *}$ & $(0.001)$ \\
\hline Male ratio & -0.008 & $(0.007)$ & $0.016^{* * *}$ & $(0.001)$ \\
\hline Adult ratio & $-0.033^{* * *}$ & $(0.009)$ & $0.005^{* *}$ & $(0.002)$ \\
\hline Mean education & $0.003^{* * *}$ & $(0.001)$ & $0.0004^{* *}$ & $(0.000)$ \\
\hline Maximum education & 0.005 & $(0.005)$ & $0.003 * * *$ & $(0.000)$ \\
\hline $\begin{array}{l}\text { Maximum education*total } \\
\text { expenditure (In) }\end{array}$ & -0.0005 & $(0.001)$ & $-0.001 * * *$ & $(0.000)$ \\
\hline \multicolumn{5}{|l|}{ Household type } \\
\hline Employed & Omitted & & & \\
\hline Unemployed & $-0.023^{* * *}$ & $(0.008)$ & -0.000 & $(0.002)$ \\
\hline Pensioners & $-0.024^{* * *}$ & $(0.006)$ & $-0.007^{* * *}$ & $(0.001)$ \\
\hline Self-employed & -0.006 & $(0.005)$ & $-0.008^{* * *}$ & $(0.001)$ \\
\hline Cluster dummies & $\begin{array}{l}F(260,5557) \\
68.997^{* * *}\end{array}$ & & $\begin{array}{l}F(266,13975) \\
3.611^{* * *}\end{array}$ & \\
\hline Constant & $0.609^{* * *}$ & $(0.057)$ & $-0.012^{* * *}$ & $(0.009)$ \\
\hline Observations & 5828 & & 14.252 & \\
\hline $\mathrm{R}^{2}$ & 0.811 & & 0.091 & \\
\hline
\end{tabular}

\section{Household-level regression}

Table 3 presents the results of the household-level regression (first-stage regression) for unit value and budget shares of cigarettes. The results of the unit values equation show that the coefficient for total expenditure is significant and it indicates that the quality elasticity of expenditure is about $0.06 \%$. In other words, households with $10 \%$ higher expenditure will buy cigarettes that are $0.6 \%$ more expensive. This result is consistent with the results from other countries ${ }^{6}$ and indicates that there is quality shading in B\&H. Thus, we use Deaton model for obtaining an unbiased estimation of cigarette price elasticity. Coefficient of the household size from unit value regression has the expected signs, unit value is lower in larger households. Male ratio is not statistically significant. Adult ratio is statistically significant and negative, which means that households with more number of adults (age 14+) buy cigarettes with lower unit value. Additionally, 'pensioner' and 'unemployed' household types spend lower amount of money on the cigarette packs, while the same does not hold for 'self-employed' households. Mean education has a significant and positive effect on unit value, meaning that a household whose average education is higher spends more money on cigarette pack. On the other hand, maximum education variable is not statistically significant, nor a variable representing interaction between total expenditure and maximum education level. Finally, cluster fixed effects are statistically significant and relatively large, confirming that spatial/time variation is pronounced.

The estimated coefficients from the budget share equation show that households with higher levels of expenditure spend higher budget share on cigarettes. Households with $10 \%$ higher expenditure spend about $0.04 \%$ points more budget on cigarettes. Budget share spent on cigarettes is larger among larger households, in households with higher shares of men and adults. Also, budget share spent on cigarettes is higher in the households where mean and maximum education is higher. It is interesting to analyse the interaction term between maximum education level of household and total expenditure, which is statistically significant and negative. Households, which at the same time have higher education level and total expenditure, spend lower budget share on cigarettes. Opposite to unit value equation, cigarette budget share in 'unemployed' household type is not statistically different compared with the 'employed' household type. 'Self-employed' households spend lower budget share on cigarettes than the 'employed' households. Similar to the unit value equation, cluster fixed effects are significant and indicate substantial variability in the budget shares between the clusters.

\section{Cluster level and price elasticity estimates}

The primary interest of Deaton procedure is to estimate price elasticity at the cluster level using cluster-level budget shares and cluster-level unit value stripped of all other factors. So, in this stage, we purge the effects of the total household expenditure and other household characteristics from the budget shares and the unit values, and then averaging across cluster. According to the procedure described in theoretical explanation of the Deaton model, this allowed us to estimate how cluster-level demand responds to change in cluster-level unit value and then price elasticity.

Results indicate a negative price elasticity of -1.366 . This means that if cigarette prices in $\mathrm{B} \& \mathrm{H}$ increase by $10 \%$, demand for cigarettes would decrease by $13.66 \%$. SE of the elasticity indicates that the value of the price elasticity is significantly 
different from and lower than zero $\left(\xi=-1.366 ; \mathrm{SE}_{\xi}=0.1741\right.$, $\mathrm{t}=-7.846$ ).

Although Deaton model is not so efficient in estimation of expenditure elasticity, as it is in case of price elasticity, still Deaton procedure offers the possibility of obtaining this coefficient as well. The estimated value of total expenditure elasticity, calculated according to the procedure described in theoretical background of Deaton model, is in line with the expectations positive and estimates at 1.129. SE of the expenditure elasticity indicates that the value of expenditure elasticity is statistically different and higher than zero $(\mathrm{SE}=0.0788, \mathrm{t}=14.330)$. In other words, if total expenditure of households is $10 \%$ higher, the demand for cigarettes will be higher for $11.29 \%$.

\section{DISCUSSION AND CONCLUSIONS}

In this paper we used the HBS data for 2011 and 2015 as well as Deaton demand model to estimate the price elasticity of cigarette consumption in B\&H. The estimated price elasticity of demand for cigarette is statistically significant at the level of $1 \%$, and amounts to -1.366 . This implies that a rise in the price of cigarettes by $10 \%$ leads to a fall in demand for cigarettes by $13.6 \%$, while all other factors remain constant. The results of the econometric estimate of elasticity of demand are more elastic compared with the results of similar surveys carried out on the sample of LMICs where the price elasticity of demand for tobacco products ranges from -0.2 to $-0.8 .^{417}$ It demonstrates that the demand for cigarettes is highly responsive to its prices and that increase in cigarette prices could reduce demand for cigarettes in $\mathrm{B} \& \mathrm{H} .{ }^{18}$ Taking into account that the main driver of cigarette price increase in $\mathrm{B} \& \mathrm{H}$ is increase in excise, high degree of responsiveness of cigarette demand to price increase suggests that the increase in excise is efficient tobacco control policy. To fully estimate the impact of cigarette price increase in excise on cigarette consumption, the future research should focus on estimation how the tobacco industry would react to changes in tobacco tax policy.

The paper provides a solid foundation for further research on tobacco industry and tobacco use in order to create and implement effective tobacco taxation policies in $\mathrm{B} \& \mathrm{H}$. As a result of the high levels of tobacco usage, B\&H faces significant health and economic consequences. Premature deaths attributable to smoking are projected to be as high as 600000 in $\mathrm{B} \& \mathrm{H}$ of about 1.2 million smokers alive today. ${ }^{19}$ Furthermore,

\section{What this paper adds}

- Our study provides important empirical evidence of a relationship between values of the elasticity of cigarette demand in relation to the change in prices. We found out that the estimated value of the elasticity of cigarette demand in relation to the change in prices is statistically significant at the level of $1 \%$, and amounts to -1.366 . This implies that a rise in the price of cigarettes by $10 \%$ leads to a fall in demand for cigarettes by $13.66 \%$, while all other factors remain constant.

- To the best of our knowledge, no existing studies in Bosnia and Herzegovina (B\&H) have analysed the elasticity of demand for cigarettes in relation to the change in prices using Deaton demand model. It demonstrates that the demand for cigarette is responsive to its prices and that increase in cigarette prices could reduce the demand for cigarettes in B\&H. non-communicable diseases account for $45 \%$ of deaths in $\mathrm{B} \& \mathrm{H} .{ }^{20}$ It is believed that if tobacco control policies are fully implemented, they would reverse those negative health trends. $\mathrm{B} \& \mathrm{H}$, like other LMICs, does not commission regular national surveys to collect data on smoking parameters and does not have a system for recording health outcomes.

\section{Limitations}

B\&H does not have a household study on annual basis. So far, household studies have been carried out four times in 2004, 2007, 2011 and 2015. The first two studies could not be taken into account because the excise policy of increasing tobacco and tobacco products' prices is only being applied in $\mathrm{B} \& \mathrm{H}$ since 2009. However, the results of our survey are confirmed by earlier research in the LMICs. Justification of implementing policy on increasing of tobacco and tobacco product prices is being confirmed too by obvious benefits on the decrease of cigarette demand in $\mathrm{B} \& \mathrm{H}$.

Contributors All authors contributed to data interpretation, revised the draft, and reviewed and approved the final version of the paper.

Funding This study was funded by the University of Illinois at Chicago's Institute for Health Research and Policy through its partnership with Bloomberg Philanthropies.

Competing interests None declared.

Patient consent for publication Not required.

Provenance and peer review Not commissioned; externally peer reviewed.

Data availability statement Data may be obtained from a third party and are not publicly available. Data from the Household Budget Surveys (2004, 2007, 2011 and 2015) may be obtained from the Agency for Statistics of Bosnia and Herzegovina upon reasonable request.

\section{ORCID iD}

Anđela Pepić http://orcid.org/0000-0002-9414-9003

\section{REFERENCES}

1 The World Atlas. Which countries smoke the most cigarettes? 2018. Available: https://www.worldatlas.com/articles/countries-that-smoke-the-most-cigarettes.html [Accessed 22 Aug 2019].

2 The World Bank. Bosnia and Herzegovina country data, 2018. Available: https://data. worldbank.org/country/bosnia-and-herzegovina?view=chart [Accessed 14 Mar 2019].

3 Petković S, Gligorić D, Vukojević B, et al. Improving tobacco Tax policies in Bosnia and Herzegovina. policy brief. November 2018. Banja Luka: University of Banja Luka, center for project management and entrepreneurship and center for entrepreneurship and technology transfer, 2018. Available: http://tobaccotaxation.org/wp-content/ uploads/2018/12/Policy-Brief-Bosnia.pdf [Accessed 8 Apr 2019].

4 Stoklosa M, Goma F, Nargis N, et al. Price, Tax and tobacco product substitution in Zambia. Tobacco Control 2018;0:1-8.

5 Chaloupka FJ, Straif K, Leon ME. Effectiveness of Tax and price policies in tobacco control. Tobacco Control 2010;20:235-8.

6 John RM. Price elasticity estimates for tobacco products in India. Health Policy and Planning 2008;23:200-9.

7 Eozenou P, Fishburn B. Price elasticity estimates of cigarette demand in Vietnam. MPRA paper No. 12779, 2001. Available: https://ideas.repec.org/p/dpc/wpaper/0509. html [Accessed 25 Oct 2018].

8 Selvaraj S, Srivastava S, Karan A. Price elasticity of tobacco products among economic classes in India, 2011-2012. BMJ Open 2015;5:e008180.

9 Deaton A. Quality, quantity, and spatial variation of price. American Economic Review 1988;78:418-30

10 Bosnia and Herzegovina Agency for Statistics. The household budget survey (HBs) data for 2011 and 2015 2018b.

11 The Household Budget Survey (HBS) is a national household based survey conducted in irregular time periods in Bosnia and Herzegovina mainly focusing on final consumption expenditure of households. The survey collects data on household expenditure for food and beverages, housing, furniture, clothing and footwear, health, transportation, communication, recreation and leisure, culture and education. In addition, basic information about household members, dwelling characteristics, household income and investment and data on social inclusion of their members were collected. Among them are data related to tobacco and alcohol consumption. For the analysis of the consumption expenditure, the Classification of Individual Consumption by Purpose (COICOP) is used. The COICOP divides consumer expenditures into twelve different divisions. The samples of chosen households were different in every year of 
surveys. It has been used two-phase stratified sampling where in the first phase were defined enumeration areas as primary sampling units and in the second phase - the households were randomly chosen from enumeration areas. The household samples were split into 12 equal size sub samplings respecting the reliability and objectiveness of the results at the end of every quartal. The methodology used in conducting the surveys were face to face interviews and self-estimation diary recorded by household's member. The interview method was used for Final Interview, Social and Health data. The self-estimation diary was used for Diary of Purchases and Self-consumption Booklet for the products which were self-produced and consumed during two weeks in the household. The survey questions related to tobacco consumption were asked in Diary of Purchases filled in by the person most familiar with the expenditures made for purchasing products, recording day by day during two weeks. The questions related to tobacco consumption are as follows: Cigarettes amount paid in BAM, Number of boxes of cigarettes spend in two weeks. Cigars - amount paid in BAM, Cigars - number of consumed pieces, Pipe tobacco and cigarette papers and other tobacco types like cut tobacco in BAM.

12 Deaton A. The Analysis of Household Surveys: A Microeconometric Approach to Development Policy. Baltimore: Johns Hopkins University Press, 1997.

13 John RM. Price elasticity estimates for tobacco and other addictive goods in India, WP 2005:003.

14 We rank the labor market activity of the household members in the following order 1) employed; 2) self-employed, 3) pensioner, 4) unemployed. If there is a member of the household which is employed, the household is labelled as "employed". If there are no employees, in the household, but there are self-employed, the household type is "self-employed". If there are no employees or self-employed, but there is a pensioner in the household, the household is marked as "pensioner, and finally if the adult household members are all inactive or unemployed the household is labelled as "unemployed".

15 Bosnia and Herzegovina agency for statistics 2018. Economics Statistics.

16 Approximately equal mean and maximum education suggests education sorting of the household members.

17 Acharya A, Angus K, Asma S. The Economics of Tobacco and Tobacco Control. In: Chaloupka FJ, Fong GT, Yürekli AA, eds. Nci tobacco control monograph series, 21. Bethesda, MD. U.S: Department of Health and Human Services, National Institutes of Health, National Cancer Institute, and World Health Organization, 2016.

18 Shang C, Lee HM, Chaloupka FJ, et al. Association between Tax structure and cigarette consumption: findings from the International tobacco control policy evaluation (ITC) project. Tobacco Control 2018;0:1-6.

19 World Health Organization. Tobacco control fact sheet for Bosnia and Herzegovina, 2016. Available: http://www.euro.who.int/_data/ assets/pdf_file/0012/312600/ Tobacco-control-fact-sheet-BosniaHerzegovina.pdf [Accessed 23 Sep 2018].

20 Ibid 2016

21 Budget shares on cigarettes is calculated as a simple average of budget share on cigarettes per households. Therefore, we first calculate budget share on cigarettes per households and then calculate simple average in order to get the average share of the budget which household spend on cigarettes. 